\title{
A Design and Optimization of a New, Three- Axis MEMS Capacitive Accelerometer with High Dynamic Range and Sensitivity
}

\author{
Bahram Azizollah Ganji, Kamran Delfan Hemmati
}

\begin{abstract}
Babol Noshirvani University of Technology, Faculty of Electrical and Computer Engineering, Babol, Iran
\end{abstract}

\begin{abstract}
In this paper a three-axis capacitor accelerometer has been designed, analyzed and optimized using microelectromechanical systems technology. The accelerometers are generally divided into three categories of single axis, two axes, and three axes in terms of their ability to measure acceleration. In the suggested structure, acceleration measurements are carried out on all three axes simultaneously using a mass and spring system, which makes it possible to achieve a high sensitivity at a low occupancy level without losing other accelerator factors. By taking difference in this structure, it is shown that each axis acceleration has a very low impact on the measured acceleration of the other two axes. If any external factor changes the value of a single capacitor, the original output of the capacitor does not change for detecting acceleration. In other words, the acceleration of any of these three axes, due to its designing features, does not influence the other two axes and the system performance cannot be disrupted by external factors. The other important characteristics of the accelerometers are dynamic range, operating frequency and sensitivity. This study covers a dynamic range up to $1000 \mathrm{~g}$ and an operating frequency up to $20 \mathrm{kHz}$. The accelerometer sensitivity is $4 \mathrm{fF} / \mathrm{g}$ in the $\mathrm{z}$ axis direction while it is $9 \mathrm{fF} / \mathrm{g}$ in the $\mathrm{x}$ and $\mathrm{y}$ axes directions. In this paper, the simulation of the structure is performed using Intellisuite software. Moreover, a multi-objective genetic optimization algorithm has been used to determine the dimensions of the constituents of the spring and the weight.
\end{abstract}

Keywords: Accelerometer; Three Axis; MEMS; Dynamic Range; Operating Frequency

\section{Zasnova in optimizacija novega troosnega MEMS kapacitivnega pospeškometra z velikim dinamičnim območjem in visoko občutljivostjo}

\begin{abstract}
Izvleček: $V$ članku je predstavljena zasnova, analiza in optimizacija kapacitivnega pospeškometra z uporabo mikro elektromehanične tehnologije. Pospeškometri so običajno deljeni v tri skupine glede na zmožnost meritve pospeška v eni, dveh ali treh oseh. V predlagani strukturi se pospešek meri simultano v vseh treh oseh z uporabo sistema mase in vzmeti, kar omogoča doseganje visoke občutljivosti pri nizki stopnji zasedenosti in brez izgube ostalih parametrov pospeška. Z vnosom različnosti v strukturo je pokazano, da pospešek v eni osi zelo malo vpliva na meritve pospeška v drugih dveh oseh. Če katerikoli zunanji vpliv spremeni vrednost kondenzatorja, se originalen izhod kondenzatorja za detekcijo pospeška ne spremeni.Z drugimi besedami povedano, pospešek ene osi, zaradi narave zasnove, ne vpliva na ostali dve osi in delovanje sistema ni podvrženo zunanjim vplivom. ostale pomembne karakteristike pospeškometrov so dinamično območje, delovna frekvenca in občutljivost. Študija obsega dinamičen razpon do $1000 \mathrm{~g}$ in delovno frekvenco 20 kHz. Občutljivost pospeškometra je 4 fF/g v z osi in 9 fF/g v x in y smeri. Simulacije so narejene s programskim paketom Intellisuite. Za določanje uteži in vzmeti je bil uporabljen več objektni optimizacijski algoritem.
\end{abstract}

Ključne besede: Accelerometer; Three Axis; MEMS; Dynamic Range; Operating Frequency

*Corresponding Author's e-mail: Kamran.delfan@gmail.com 


\section{Introduction}

An accelerometer is a device that measure proper forces of acceleration and is one of the most important sensors widely used in modern systems. Accelerometers can provide a completely independent positioning device which detects position with reference to an original point without any use of a receiver or transmitter from a satellite or other sources. This feature is used in the navigation field. Furthermore, the efficiencies of engine, torque transfer system, and brake system can be evaluated via accelerometer. Accelerometers can be employed to measure the vibrations of automobiles, machines, buildings, control systems process, and device installation safety (Yuan et al. 2006; Marek et al. 2005).

These applications have all focused on making accelerometers smaller (i.e., occupying less room) and more sensitive. Generally, there are several types of MEMS $^{1}$ accelerometers: piezoelectric, piezoresistive, resonance oscillator, capacitive, SERVO, and tunneling phenomenon (Allen. 2005; Beeby et al. 2004). The aim of this study is to obtain a three-axis accelerometer with high dynamic range, high operating frequency, and high sensitivity with low occupancy level using MEMS technology. Compared with other types of accelerometers, the capacitive accelerometers have the several advantages such as high precision to a micro-g range, high sensitivity, proper response to the fix input, proper performance against noise, low temperature sensitivity, applicable in a wide range of temperature, low power consumption, low losses and simplicity of mechanical structure (Ashok Kumar et al. 2017; Lammel. 2015).

Up to now, many capacitive accelerometers have been designed and created. For example, (Kraft. 1996) proposed a single one-axis capacitive accelerometer which can measure acceleration in the direction of one axis. In order to have a good sensitivity in this structure, largearea capacitive planes are required. Therefore, the total occupancy level for making sensor is too high. Besides, this structure has a low dynamic range. In (Moghadam et al. 2014), a one-axis accelerometer with folded arms was presented. In this accelerometer, by reducing the spring constant, the sensitivity increase. In this scheme, reduced spring rigidity results low operating frequency and dynamic range of the sensor. (Terzioglu et al. 2015) Introduced a one-axis comb-like accelerometer. However, this accelerometer was limited to measure acceleration in a single axis direction and was thus inappropriate for applications that would require acceleration measurements in two or three axes directions. In (Ta- vakoli and Sani. 2015), a two-axis accelerometer was developed, in which the maximum capacitor changes was $975 \mathrm{fF}$. The maximum measurable acceleration was $325 \mathrm{~g}$. A three-axis accelerometer without detecting the acceleration direction was offered in (Benevicius et al. 2013). In this accelerometer, in order to have a $3 \mathrm{fF} / \mathrm{g}$ sensitivity and $1000 \mathrm{~g}$ acceleration in the $z$ axis direction, a dimension of at least $850 * 850$ um was needed for the plane beneath the weight. This condition was realized by designing a proper spring. The main problem in (Benevicius et al. 2013) was calculating acceleration in the direction of the other two axes with a very low sensitivity due to the change of capacitance caused by the change in the overlap area. For example, with 1um displacement, the capacitor value changed only about $2 \%$, and for having a $3 \mathrm{fF} / \mathrm{g}$ sensitivity, only the acceleration of $20 \mathrm{~g}$ could be measured. Besides, this accelerometer could not differentiate accelerations of different axes and could not realize the axis direction of the applied acceleration. A three-axis accelerometer composed of three separate accelerometers was presented in (Tez et al. 2015). This structure had three separate parts with around $0.4 \mathrm{~mm}^{2}$ surface area. In this context, by considering the required space for spring installation, a capacitor plane of around 500*500um could be used in the $z$ axis direction. Considering the sensitivity of $3 \mathrm{fF} / \mathrm{g}$, the sensitivity of the maximum measurable acceleration would be $450 \mathrm{~g}$. Similarly, it can be proved that the required acceleration in (Tez et al. 2015) could not be satisfied along the other two axes.

In this paper a new structure is developed to cover a dynamic range up to $1000 \mathrm{~g}$ and an operating frequency limit of up to $20 \mathrm{kHz}$ with the sensitivity constraint of $3 \mathrm{fF} / \mathrm{g}$ in all the three axes. Note that the suggested scheme, having the aforesaid advantages, has also kept a proper occupying level, which cannot be observed in any of the previous three-axis accelerometer structures. Moreover, this structure is able to separately measure accelerations along all the three axes. The acceleration effect of each axis on the measured accelerations of the other two axes is zero. Note that the accelerometer proposed in this paper is validated by simulation and has not entered the construction stage.

The present paper is organized as follows. In Section 2 , principles of the accelerometer performance are presented. Section 3 focuses on the design of the proposed accelerometer. In this section, a new structure is indeed provided for three-axis accelerometers. In Sections 4 and 5 , by analyzing the relations concerning this structure, the outputs are calculated and diagrammed and the results are then compared with other studies.

${ }^{1}$ Micro-electromechanical Systems(MEMS) 


\section{Analysis of MEMS accelerometer}

Mechanical model of an accelerometer is shown in Fig. 1. This model is mainly comprised of a hanging weight with a defined mass, one (or several) spring(s), a fluid damper (mostly air), and a body which in fact forms the mechanical part of the accelerometer.

From Fig. 1, the relation between force (F) and displacement of the pending weight can be expressed as follows (Bao and Yang, 2007):

$$
F(t)=M \frac{d^{2} x}{d t^{2}}+C \frac{d x}{d t}+K x
$$

Where $\mathrm{x}$ is mass displacement from its original state, $\mathrm{C}$ is damper coefficient, $M$ is mass, and $\mathrm{k}$ is spring constant.

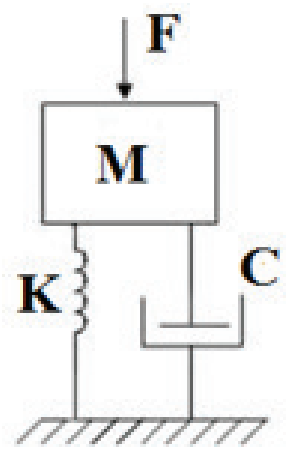

Figure 1: Mechanical model of the accelerometer (Acar and Shkel. 2007).

Force, $F$, can be generated by applying acceleration to the structure, and accordance with Newton' second law of motion $(F=m a), a$ is the same acceleration that must be measured by the accelerometer.

Now, in order to obtain the amount of weight displacement due to the applied acceleration, Laplace transformation is to be taken from the differential equation of relation 1 and Newton's second law of motion to achieve a transition function with the applied acceleration as its input and the displacement as its output, thus (Bao and Yang, 2007):

$H(s)=\frac{x(s)}{a(s)}=\frac{1}{s^{2}+\frac{c}{m} s+\frac{k}{m}}$

For frequencies below natural frequency, the following linear relation can be used for the mass and spring system (Acar and Shkel. 2007):

$$
\frac{x}{a}=\frac{m}{k}
$$

The natural frequency of mass-spring-damper is as follows (Momen et al. 2016):

$f=\frac{1}{2 \pi} \sqrt{\frac{k}{M}}$

Eq. 3 shows the mechanical sensitivity of the system in the direction of the applied acceleration, which is equal to the value of weight displacement caused by the application of unit acceleration. As this relation shows, for increasing mechanical sensitivity, it is required to increase mass and decrease the spring rigidity coefficient; however, increased mass and decreased spring rigidity coefficient reduce the natural frequency of the spring according to relation 4. Therefore, these two issues must be kept in balance in the designing process.

In accelerometer sensors, acceleration is usually given in $\mathrm{g}$. In capacitive accelerators, sensitivity is defined as the ratio of the capacitor changes due to a 1-g acceleration, and thus (Momen et al. 2016):

$$
s=\frac{\Delta C}{g}=\frac{\Delta C}{x} \times \frac{x}{g}
$$

If the field effect of the electrodes margin is disregarded, changes in capacitances due to air distance between electrodes can be expressed as follows (Bao and Yang, 2007):

$\Delta C=\varepsilon A\left(\frac{1}{d-x}-\frac{1}{d+x}\right) \rightarrow x^{2}<<d^{2} \rightarrow 2 \varepsilon$

Where $d$ is the original air distance, A shows the total area of the planes comprising capacitor, and $x$ is displacement from original state. From Eq. 6, it is clear that the change of the capacitance is proportional to the mass deviation, which is due to the acceleration applied to the system under the assumption that the deviation is small (Momen et al. 2016).

Besides, the most important parameters in accelerometers are dynamic range and operating frequency. The dynamic range refers to an acceleration range in which the accelerometer can do the measurements. The accelerometer operating frequency is the point in which the amount of applied acceleration varies rapidly. This acceleration can be measured using a high-operating frequency accelerometer (namely, an accelerometer that responds quickly to the rapid changes) (Bao and Yang, 2007). 
In what follows, an accelerometer is designed, which is able to measure acceleration ranging from $-1000 \mathrm{~g}$ to $+1000 \mathrm{~g}$ and which covers a $20-\mathrm{KHz}$ frequency limit.

\section{Design of a new Accelerometer}

In this section, the suggested structure is designed. To this end, first the capacitive planes and then the spring are designed. Finally, the complete structure is presented.

\subsection{Designing of capacitive planes}

The changes of capacitor in accelerometers are caused by three motions: changes in the overlapping of surfaces, air distance, and dielectric overlapping (Momen et al. 2016). The highest sensitivity is caused by the change of air distance. Therefore, air distance change parameter has been applied in all the three axis directions as the main distinguishing feature of the suggested scheme, compared to the previous methods. There are three parallel planes in the $z$ axis direction: two of them are fixed and the third and the middle one is mobile. By making difference in the capacitance measurement, the two parallel upper and lower planes can minimize the noise effect on the obtained value. As an innovation, our suggested scheme is capable of measuring acceleration in the $\mathrm{x}$ and $\mathrm{y}$ axes directions. When the acceleration in the $y$ axis direction is applied, as shown in Fig. 2, the mobile plane and the combs will be moved in the direction of the applied acceleration, and resultantly the values of capacitors $\mathrm{C} 1$ and $\mathrm{C} 3$ increase due to small air gap, while capacitors $C 2$ and $C 4$ have lower values than their original states. Using a single parameter, the following equation shows the total value of capacitive changes induced by the acceleration in the said axis direction:

$\mathrm{Cy}=\mathrm{C} 1+\mathrm{C} 3-(\mathrm{C} 2+\mathrm{C} 4)$

When no acceleration exists in the y direction, the result of the above relation will also be zero. If acceleration is applied in the positive direction of the $y$ axis, the result will be positive; if acceleration is applied in the negative direction of the $y$ axis, the result will be negative. If any acceleration other than the one in the desired axis direction is applied to the system, then the obtained value from the relation will be zero - although the value of any of the capacitors might change.

Besides, if the values of all the capacitors, due to any external factor (such as magnetic field), change similarly, the $\mathrm{Cy}$ is fixed and stable. For calculation of the applied acceleration in the $x$ axis, as shown in Fig. 2, there are four capacitors C5, C6, C7, and C8. The total value of capacitor variation when acceleration is applied in the $\mathrm{x}$ axis direction can also be shown by a single parameter as follows:

$C_{x}=C 5+C 7-(C 6+C 8)$

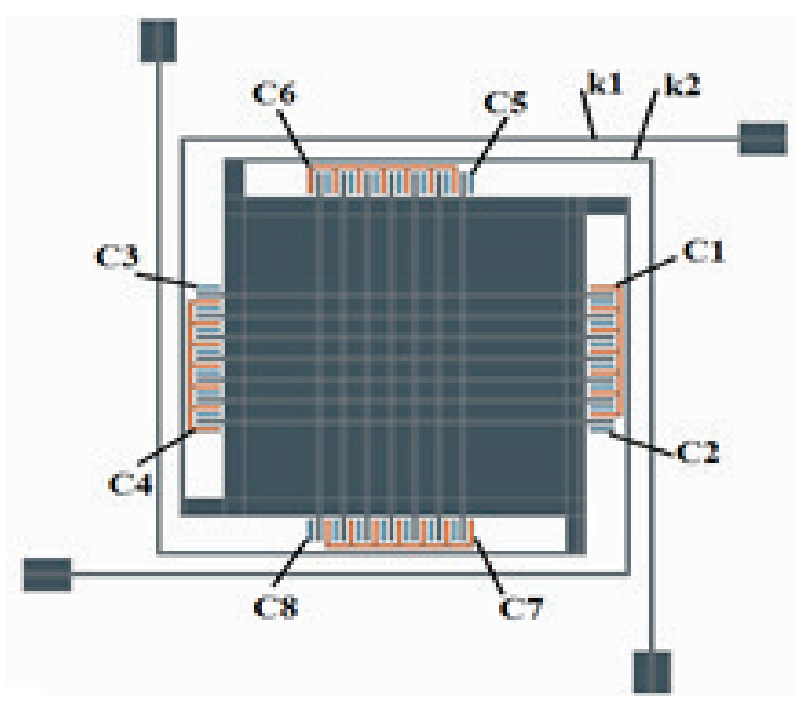

Figure 2: Acceleration measurement in the y axis direction

As said before, when acceleration is applied to one of the three axes directions, it exerts a zero effect on the other two axes. For example, if the acceleration is applied to the set in the $x$ direction, the values of capacitors C5 and C7 increase (as the air distance between the two planes decreases) while the values of capacitors $\mathrm{C} 6$ and $\mathrm{C} 8$ decrease. Therefore, the $\mathrm{Cx}$ value would change from zero to a positive number in proportion to the applied acceleration. Moreover, since this value is positive, it can be inferred that the applied acceleration is in the positive direction of the $x$ axis. A question might arise as what happens to the Cy value.

For all the four capacitors C1, C2, C3, and C4, the air distance would not change. The values of capacitors C1 and $\mathrm{C} 2$ are increased by increasing their overlapping. On the other hand, the values of capacitors C3 and C4 similarly decrease due to decreased overlapping surface, and so the Cy value does not change.

It is resulted that the acceleration applied in the $x$ direction does not affect the Cy value. Here, it can also be shown that the acceleration used in each of the three axes directions has no effect on the measured capacitance for the other two axes directions.

For calculating the applied acceleration in $z$ axis, there are two capacitors, which are formed using upper and lower surfaces of the mass bulk. There are also two fixed plates with air gap, which are placed at the ends 
of the mass bulk and which complete the structure of the two capacitors. By Assuming that the capacitor between the upper surface of mass bulk and the upper fixed plane is C9 and the lower capacitor is C10, we have:

$\mathrm{Cz}=\mathrm{C} 9-\mathrm{C} 10$

$C_{z}$ is actually in proportion to the acceleration applied in the $z$ axis direction. Here also, if acceleration is applied in the directions of the $x$ and the $y$ axes, $C_{z}$ value remains unaffected.

\subsection{Spring Design}

Springs are components in the vibrational systems that react to the displacement, and since spring mass is insignificant compared to the main mass, this mass is usually disregarded. Force is generated in the spring when a relative displacement occurs in its two ends. For a linear spring, the spring force is proportional to the amount of deformation that is obtained from relation $\mathrm{F}=\mathrm{K}^{*} \mathrm{X}$, where $\mathrm{F}$ is the spring force, $\mathrm{X}$ the spring deformation amount (displacement of an end with respect to the other end of the spring), and $\mathrm{K}$ is the spring rigidity or spring constant.

Elastic elements, such as beams, act as a spring. For example, take a cantilevered beam with an end mass, m, as shown in Fig. 3. The beam mass (with respect to the mass $\mathrm{m}$ ) has been disregarded.

Static deformation of the beam at its free end is expressed as follows:

$\delta_{s t}=\frac{W L^{3}}{3 E I}$

Where $\mathrm{W}=\mathrm{mg}$ is the weight of mass $\mathrm{m}$, E elasticity module, I inertia moment of cross section, and $L$ is the beam length. Therefore, the spring constant is:

$K=\frac{W}{\delta_{s t}}=\frac{3 E I}{L^{3}}$

Therefore, the presented system in Fig. 3 can be considered a mass and spring system (Fig. 4), for which the

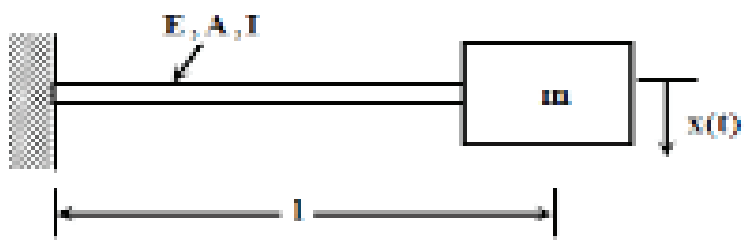

Figure 3: A cantilevered beam and mass of its end value of the spring constant is calculated in relation 11 (Marek et al. 2005).

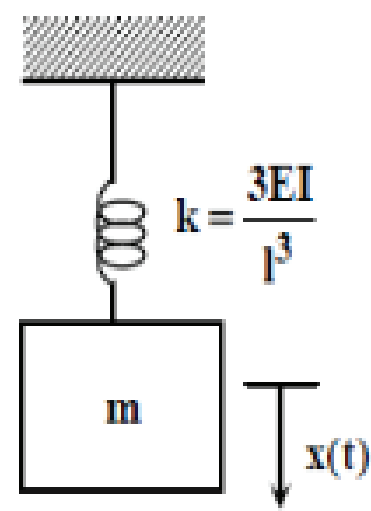

Figure 4: The mass and spring system (Beeby et al. 2004).

\section{The complete structure of the suggested protocol}

The upper schema of the complete structure of this protocol is given in Fig. 2. This structure, in addition to the combination of the capacitors said before, has four parallel springs, each of which is composed of two series springs. With regard to the explanations about spring designing, in calculations, the total rigidity of all the eight springs can be equated into one singular spring. The spring rigidity is calculated differently for each of the $x$, the $y$, and the $z$ axes directions. In calculating spring rigidity in the $z$ axis direction, springs $k 1$ and $k 2$ are series and their equivalent spring is parallel with three other similar springs. Here, first the movement perpendicular to the plane is calculated for one of the four springs. This movement is caused by three displacements: 1) displacement resulting from spring $k 1,2)$ displacement resulting from spring $k 2$, and $c$ ) displacement resulting from the torsion (due to the torque entered from $\mathrm{k} 1$ at the connection section of two springs) of spring $k 2$, where the most displacement caused by it goes towards one end of spring k1 which is connected to the mass bulk. Regarding the spring rigidity equation for a cantilevered beam, the displacement due to spring $\mathrm{k} 1$ alone can be obtained from equation 12 .

$\delta_{k 1}=\frac{p l_{1}^{3}}{3 E I_{1}}$

Where $p$ is the imposed force from the mass bulk, and I, E, and I are respectively the length, Young's modulus (i.e., axial elastic modulus), and the inertia moment of 
the spring (the index shows the spring number). In the same way, the displacement due to spring $\mathrm{k} 2$ alone can be obtained from equation 13 .

$$
\delta_{k 2}=\frac{p l_{2}^{3}}{3 E I_{2}}
$$

Furthermore, the displacement due to the torsion (owing to the entered moment from $\mathrm{k} 1$ at the connecting point of the two springs) of spring $\mathrm{k} 2$ can be achieved from equation 14 (Bao and Yang, 2007).

$$
\delta_{\theta}=\frac{p l_{1}^{2} l_{2}}{G \beta b c^{3}}
$$

In the above relation, $G, \beta, b$, and $c$ are shear elastic modulus, constant coefficient from table, cross section, and thickness of the beam section related to spring $\mathrm{k} 2$, respectively. As such, the mass bulk displacement is produced from the sum of these three displacements. Since the spring rigidity is the ratio of the force on the displacement, we can obtain the spring rigidity of one of the four springs in the $z$ axis direction as follows:

$$
k_{z}=\frac{9 E I_{1} I_{2} G \beta b c^{3}}{3 G \beta b c^{3}\left(l_{1}^{3} I_{2}+l_{2}^{3} I_{1}\right)+9 E I_{1} I_{2} l_{1}^{3}}
$$

In this relation, I signifies the inertia moment of the cross section or the second surface torque, which is obtained from equation 16 (Beeby et al. 2004).

$$
I=\frac{w t^{3}}{12}
$$

In the above formula, $w$ is the cross section and $t$ is its thickness. By substitution of equation 16 into equation 15 , the constant value of one of the four parallel springs in the $z$ axis direction is achieved. Since the value of an equivalent spring for a number of parallel springs is obtained from the summation of their values, the final value of the equivalent spring in the $z$ axis direction is equal to the value obtained for any of the springs:

$$
K_{z}=\frac{12 E G \beta b w_{1} t_{1}^{3} w_{2} t_{2}^{3} c^{3}}{G \beta b c^{3}\left(l_{1}^{3} w_{2} t_{2}^{3}+l_{2}^{3} w_{1} t_{1}^{3}\right)+E w_{1} t_{1}^{3} w_{2} t_{2}^{3} l_{1}^{3}}
$$

For calculation of the spring constant in the $\mathrm{x}$ axis direction, Fig. 5 is considered which shows two of the total four springs. (Note that the calculation of the spring constant in this axis is completely different from that of the $z$ axis. For example, while $W_{1}$ was formerly regard- ed as the beam width, it is here assumed as thickness since the direction of movement is perpendicular to the $z$ axis.) These two springs are parallel but have dissimilar effects in the direction of $x$ axis. Therefore, their constants must be separately calculated and added together. Due to the fact that the other two springs, versus the desired axis, are symmetrical and parallel to these two springs, it is simply enough to double the obtained value so that the spring constant along the $x$ axis can be attained.
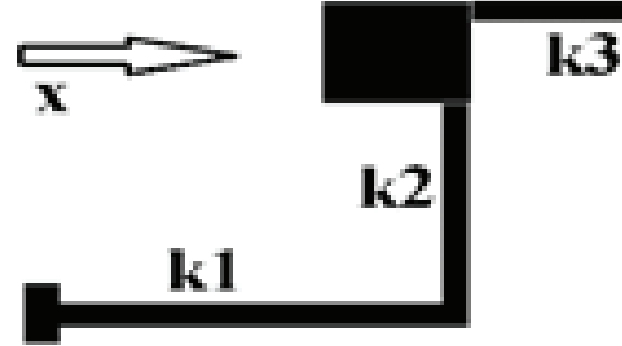

Figure 5: Two of the four influential springs in the $x$ axis direction

Due to the existence of symmetry in this scheme, spring rigidity in the $y$ axis direction is equal to that in the $x$ axis direction. Hence, the equivalent spring rigidity in the direction of this axis can be written as follows:

$$
K_{x, y}=6 E \frac{I_{1} I_{2} l_{4}^{3}+I_{4}\left(I_{1} l_{2}^{3}+3 I_{2} l_{1} l_{2}^{2}\right)}{l_{4}^{3}\left(I_{1} l_{2}^{3}+3 I_{2} l_{1} l_{2}^{2}\right)}
$$

\section{Analysis of the suggested accelerometer}

Up to now, the accelerometer structure has been designed. In this section, the suggested structure is analyzed. The analysis involves extraction of the natural frequency of the system along all the three axes, extraction of the output relations for the $x$ and the $y$ axes, as well as the extraction of output relations for the $z$ axis.

\subsection{Extraction of the natural frequency of the suggested accelerometer}

By substituting the spring rigidity relations obtained in the previous section, the natural frequency of the system along all the three axes can be attained. For example, from equations 4 and 17, the natural frequency of the system in the $z$ axis direction is:

$f_{z}=\frac{1}{2 \pi} \sqrt{\frac{\frac{12 E G \beta b w_{1} t_{1}^{3} w_{2} t_{2}^{3} c^{3}}{m}}{m} c^{3}\left(l_{1}^{3} w_{2} t_{2}^{3}+l_{2}^{3} w_{1} t_{1}^{3}\right)+E w_{1} t_{1}^{3} w_{2} t_{2}^{3} l_{1}^{3}}$ 
Using equations 4 and 18, the natural frequency of the system in the $x$ and the $y$ axes directions is:

$f_{x, y}=\frac{1}{2 \pi} \sqrt{\frac{6 E \frac{I_{1} I_{2} l_{4}^{3}+I_{4}\left(I_{1} l_{2}^{3}+3 I_{2} l_{1} l_{2}^{2}\right)}{l_{4}^{3}\left(I_{1} l_{2}^{3}+3 I_{2} l_{1} l_{2}^{2}\right)}}{m}}$

\subsection{Extraction of output relations for the z axis}

For calculation of the sensitivity, it is first required to calculate the capacitive changes due to displacement. In the $z$ axis direction, two capacitors are used which are made by the upper and the lower planes between the main plane of the mass, which is mobile, and their values are calculated from equations 21 and 22 (Acar and Shkel. 2007).

$$
\begin{aligned}
& C_{z 1}=\frac{\varepsilon A_{z}}{d_{z}-z} \\
& C_{z 2}=\frac{\varepsilon A_{z}}{d_{z}+z}
\end{aligned}
$$

Where $A_{z}$ is the area of the plane that makes the capacitor between the main mass and the fixed planes for the formation of the $z$ axis capacitor, $d_{z}$ shows the original air distance (without applying acceleration), and $z$ is the amount of displacement owing to the applied acceleration in this axis direction. Therefore, capacitor changes along the $z$ axis is a result of the difference between these two values, and hence:

$$
\Delta C_{z}=C_{z 1}-C_{z 2}
$$

By substituting equations 21 and 22 into equation 23, we have

$$
\Delta C_{z}=\varepsilon A_{z} \frac{2 z}{d_{z}^{2}-z^{2}}
$$

Here, displacements which are much smaller than the original air distance are intended, and the term $z^{2}$ can be disregarded relative to $d_{z}^{2}$. In this context, the following relation can be expressed with a good approximation.

$\Delta C_{z}=\frac{2 \varepsilon A_{z}}{d_{z}^{2}} z$

This relation shows that in the original displacements (as long as the amount of displacement relative to the original air distance is small), a linear relation exists between the capacitor changes and displacement in the $z$ axis direction. Therefore, by replacing equations 17 and 25 into equation 5 , the sensor sensitivity in the $z$ axis direction can be achieved:

$$
=\frac{\varepsilon A_{Z} m G \beta b c^{3}\left(l_{1}^{3} w_{2} t_{2}^{3}+l_{2}^{3} w_{1} t_{1}^{3}\right)+E w_{1} t_{1}^{3} w_{2} t}{6 E G b b w_{1} t_{1}^{3} w_{2} t_{2}^{3} c^{3} d_{Z}^{2}}
$$

From equation 26, it can be concluded that the accelerometer sensitivity depends on the original capacitor value, mass of the weight, original air distance, and the elements influencing the spring constant. If acceleration is applied in the $z$ axis direction, the resulting displacement can be calculated as follows:

$Z=\frac{m \times a_{z}}{k_{z}}$

Where $a_{z}$ is the applied acceleration, $m$ is the weight mass, and $k_{z}$ is the spring rigidity in the $z$ axis direction which has been calculated above.

The mechanism for the accelerometer performance is that, by applying acceleration, the weight moves and resultantly the capacitive planes also move, which leads to the change of capacitance. Accordingly, by measuring the amounts of capacitor changes using a capacitor tester, one must be able to determine the amount of the applied acceleration. To do so, it is required to define a function in which capacitor changes are used as independent variable and its output value is the applied acceleration:

$a_{z}=f\left(\Delta c_{z}\right)$

To obtain such a relation, the spring rigidity from equation 17 is substituted in equation 27 and the value of acceleration is taken from equation 3 , thus:

$x_{z}=\frac{6 d_{z}^{2} E G \beta b w_{1} t_{1}^{3} w_{2} t_{2}^{3} c^{3}}{m \varepsilon A_{z} G \beta b c^{3}\left(l_{1}^{3} w_{2} t_{2}^{3}+l_{2}^{3} w_{1} t_{1}^{3}\right)+E w_{1} t_{1}^{3} w_{2} t_{2}^{3} l_{1}}$

As is clear from the above relation, a linear relation exists between the applied acceleration and the capacitor changes, and by knowing the value of the capacitor changes, the applied acceleration can be calculated.

\subsection{Extraction of output relations for the $x$ and the $y$ axes}

Due to the existence of shape symmetry, calculations concerning the output relations for the $x$ and the $y$ axes are similar. As said before, the same springs, which 
were used in the $z$ axis direction, are simultaneously used for these two axes. This is a good advantage of the suggested protocol because it reduces the occupancy level of the scheme. Based on the explanations in the previous section, for calculating capacitor sensitivity, it is sufficient to calculate capacitor changes due to displacement. In the y axis direction, four capacitors are used. (In these relations, index $y$ is used. For the $x$ axis, the calculations are the same, and so they are not repeated.) The amounts of these four capacitors can be obtained from relations 30 to 33 (Acar and Shkel. 2007):

$$
\begin{aligned}
& C_{1}=\frac{\varepsilon n_{f} A_{s h}}{d_{y}-y} \\
& C_{2}=\frac{\varepsilon n_{f} A_{s h}}{d_{y}+y} \\
& C_{3}=\frac{\varepsilon n_{f} A_{s h}}{d_{y}-y} \\
& C_{4}=\frac{\varepsilon n_{f} A_{s h}}{d_{y}+y}
\end{aligned}
$$

Where $A_{s h}$ is the area of the plane forming the onecomb capacitor, $d_{y}$ is the original air distance between the combs (without applying acceleration), $y$ is the amount of displacement by applying acceleration in this axis direction, and $n_{f}$ is the number of fingers on each side. Therefore, the capacitor changes in the $y$ axis direction can be expressed as follows:

$$
\Delta C_{y}=C_{1}+C_{3}-C_{2}-C_{4}
$$

By substituting equations 30 to 33 into equation 34, we have:

$$
C_{y}=\frac{4 n_{f} \varepsilon A_{s h} y}{d_{y}^{2}-y^{2}}
$$

Here also, displacements that are much smaller than the original air distance are attended and the term $y^{2}$ can be omitted relative to $d_{y}^{2}$. With a good approximation, we can write:

$$
\Delta C_{y}=\frac{4 n_{f} \mathcal{E} A_{s h}}{d_{y}^{2}} y
$$

With an argumentation similar to the calculations used for the $z$ axis section, we can arrive at the sensitivity relation, and thus: $s_{y}=\frac{2 n_{f} \varepsilon A_{s h} m l_{4}^{3}\left(I_{1} l_{2}^{3}+3 I_{2} l_{1} l_{2}^{2}\right)}{3 d_{y}^{2} E I_{1} I_{2} l_{4}^{3}+I_{4}\left(I_{1} l_{2}^{3}+3 I_{2} l_{1} l_{2}^{2}\right)}$

Similarly, a function can be defined here in a way that the capacitor changes are its independent variable and its output is the applied acceleration:

$a_{y}=\frac{3 d_{y}^{2} E I_{1} I_{2} l_{4}^{3}+I_{4}\left(I_{1} l_{2}^{3}+3 I_{2} l_{1} l_{2}^{2}\right)}{2 m n_{f} \varepsilon A_{s h} l_{4}^{3}\left(I_{1} l_{2}^{3}+3 I_{2} l_{1} l_{2}^{2}\right)} \times \Delta c_{y}$

\section{Result and discussion}

In this section, the proposed accelerometer simulation in Intellisuite software will be addressed, to prove the validity of the relationships extracted in the previous section. For this simulation, the dimensions of the various parts of this accelerometer were designed manually, with trial and error, and the results of this design are shown in Table 1. The output of the simulation is shown in Fig. 6 . As can be seen in Fig. 6 and Table 1, the displacement value is $0.44 \mu \mathrm{m}$ due to the acceleration of $1000 \mathrm{~g}$, which is fully match with the results of the relationships presented in the previous section, thus proving the validity of the relationships extracted in this paper.

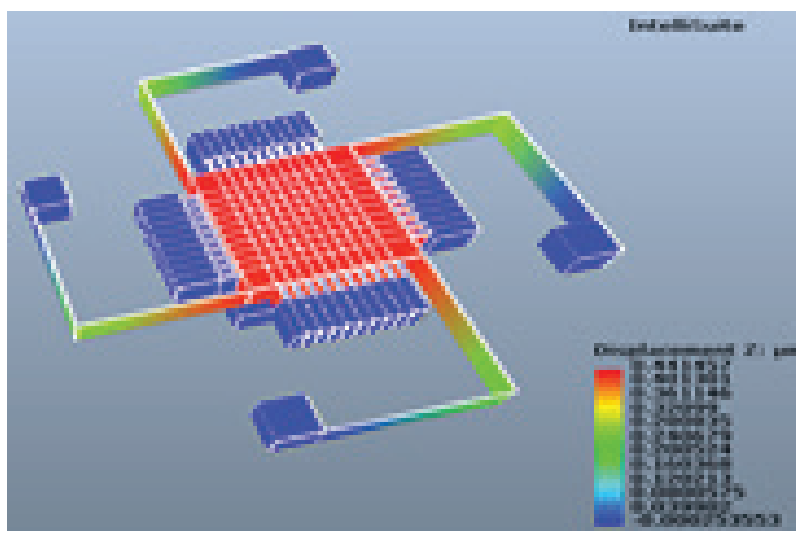

Figure 6: Simulation of the proposed accelerometer in Intellisuite software

So far, enough confidence has been gained that the analytical relationships are correct. We are now looking to extract the best possible dimensions for different parts of the accelerometer. An optimization algorithm is used for this purpose. In the suggested accelerometer, the mass bulk is square and hence a proper size must be found for its side. Therefore, the side of the mass bulk is a variable that needs to have the best value. 
Table 1: Comparison between values obtained from analytical relationships and values obtained from simulation

\begin{tabular}{|c|c|c|c|c|c|c|c|}
\multicolumn{4}{|c|}{ Movement with 1000g acceleration } & \multicolumn{3}{c|}{$\begin{array}{c}\text { Capacitor changes by applying } 1000 \mathrm{~g} \\
\text { acceleration }\end{array}$} & sensitivity \\
\cline { 2 - 9 } & $\mathrm{X}$ & $\mathrm{Y}$ & $\mathrm{Z}$ & $\mathrm{X}$ & $\mathrm{Y}$ & Z & Max. \\
\hline Calculations & $.44 \mathrm{um}$ & $.44 \mathrm{um}$ & $.44 \mathrm{um}$ & $9.31 \mathrm{pf}$ & $9.31 \mathrm{pf}$ & $4.2 \mathrm{p}$ & $9.31 \mathrm{fF} / \mathrm{g}$ \\
\hline simulation & $.441 \mathrm{um}$ & $.443 \mathrm{um}$ & $.441 \mathrm{um}$ & $9.3 \mathrm{pf}$ & $9.28 \mathrm{pf}$ & $4.19 \mathrm{pf}$ & $9.3 \mathrm{fF} / \mathrm{g}$ \\
\hline
\end{tabular}

The thickness of the mass bulk and of the spring must be equal so that the creation of this design can be accomplished. The value of this thickness is considered the second variable in this optimization. Besides, the width of the springs is assumed as the third variable. In order to facilitate the construction process, the widths of the two springs are presumed to be equal. The lengths of springs $k 1$ and $k 2$ are regarded as the fourth and the fifth variables, respectively, the values of which are highly influential in the accelerometer output.

In order to achieve the best values for the aforesaid variables, the present study has made use of multi-purpose optimization algorithm which is made of NSGA2 and SPEA algorithms - as presented in (Delfan Hemmati et al. 2012). This algorithm must search these five variables in a way that the best answers for the accelerometer characteristics can be found.

After running the algorithm, several answers were achieved, which are the members of Pareto front. The Pareto front members are some individuals from the population of each generation which are not overcome by any other member (that is, there is no other member in the population which is superior to them in terms of all the objective functions) (Delfan Hemmati et al. 2012). After running the shape algorithm, the Pareto front members are shown in the output (Fig. 7). In this figure, the horizontal axis (first target) shows the dy-

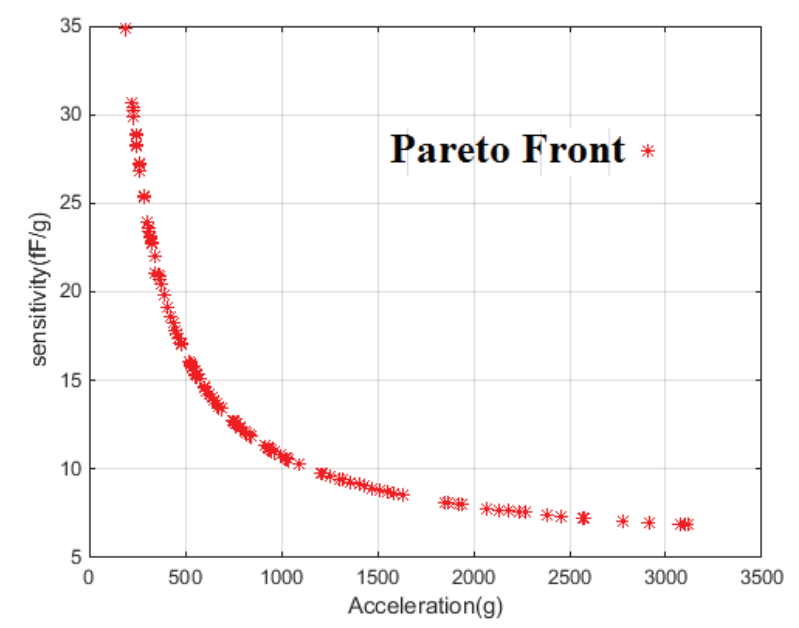

Figure 7: Members of the Pareto Front after optimization namic range and the vertical axis (second target) shows the sensitivity of each response. Out of all the individuals shown in Fig. 7, three answers have been selected, which are given in Table 2 .

Table 2: Optimization results

\begin{tabular}{c|c|c|c|c|}
$\begin{array}{c}\text { length and } \\
\text { Width of } \\
\text { Mass }\end{array}$ & $\begin{array}{c}\text { Total } \\
\text { Thickness }\end{array}$ & $\begin{array}{c}\text { Width } \\
\text { of } \\
\text { Spring }\end{array}$ & $\begin{array}{c}\text { Length of } \\
\text { Spring 1 }\end{array}$ & $\begin{array}{c}\text { Length of } \\
\text { Spring 2 }\end{array}$ \\
\hline 697 & 57 & 41 & 196 & 199 \\
\hline 699 & 53 & 40 & 261 & 230 \\
\hline 697 & 44 & 32 & 343 & 378 \\
\hline
\end{tabular}

Up to now, the values required for the five variables of mass bulk side, thickness, spring width, length of spring 1, and length of spring 2 have been obtained using the optimization algorithm. In Table 3, characteristics of the suggested accelerometer are compared to those of the previously designed accelerometers in the literature. As is observed, our proposed scheme has a good advantage over the previous ones recorded in the literature.

In order to confirm the correctness of the above relations, one of the optimization responses is here selected. This response has been completely simulated in the IntelliSuite software and the output results have been diagrammed as follows. By applying acceleration in all the three axes directions simultaneously in the range from - 1000 to +1000 , the value of displacement of the suspending mass is measured moment by moment as shown in Fig. 8.

Moreover, the amount of the capacitance variations due to the displacement of the suspending mass is shown in Fig. 9. Obviously, displacements in the range below 0.5 microns are acceptable since the capacitors changes linearly in this range.

Fig. 10 shows the capacitance variations due to the application of acceleration in the $z$ axis direction. In this figure, a comparison is made between the values obtained from optimization and the original values resulting from the trial and error. As shown in the figure, the original value of sensitivity in the $z$ axis direction is $3.9 \mathrm{fF} / \mathrm{g}$ which has hanged to $4.5 \mathrm{fF} / \mathrm{g}$ after the optimization. 
Furthermore, as is clear from Fig. 11, the amount of sensitivity in the $x$ and the $y$ axes directions has originally been $9 \mathrm{fF} / \mathrm{g}$, which has then changed to $10.6 \mathrm{fF} / \mathrm{g}$ due to the optimization.

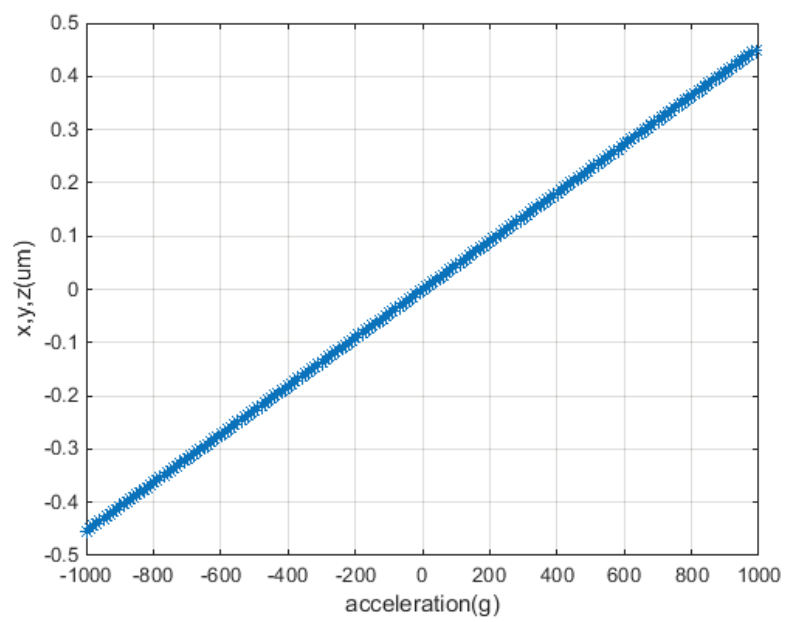

Figure 8: Displacement due to the application of acceleration in all the three axes directions

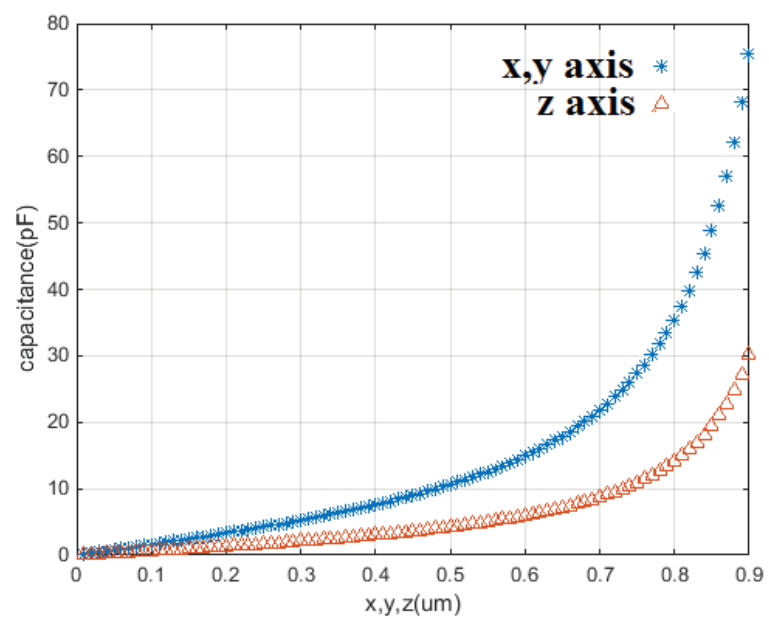

Figure 9: Capacitance variations by applying the displacement of the suspending mass

\section{Conclusion}

The present study has designed, analyzed, and optimized a new three-axis capacitor accelerator using microelectromechanical system technology. That a sensor can identify different acceleration directions, in addition to measuring them, is of paramount importance. In this structure, acceleration measurements in all the three axes directions are conducted along with the use of a mass and spring system, hence providing a high sensitivity, at the minimum occupancy level, without the loss of any other accelerometer factors. In designing this accelerometer, 10 capacitive groups are

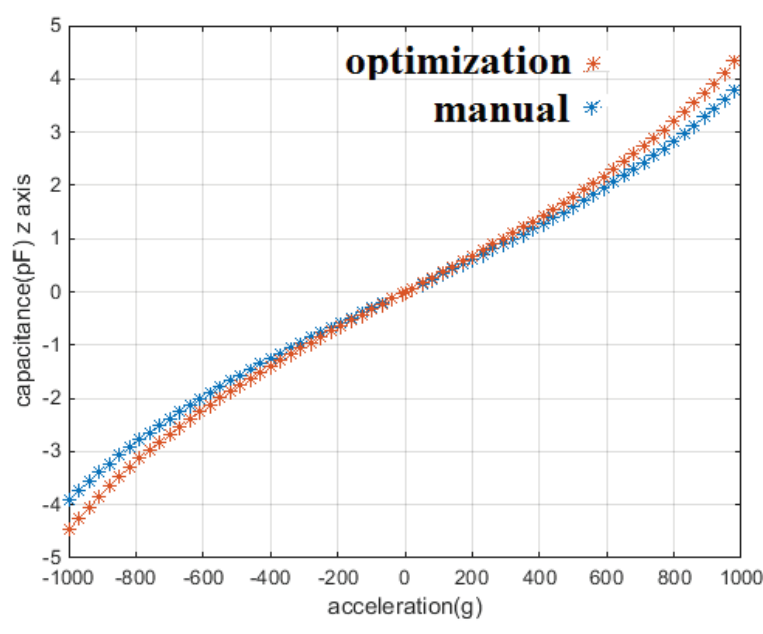

Figure 10: Capacitance variations after applying acceleration in the $z$ axis direction

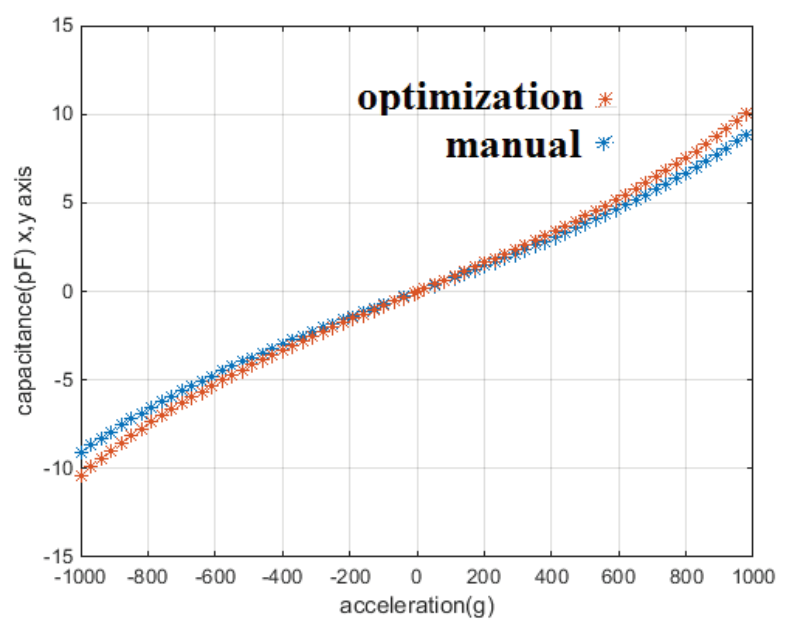

Figure 11: Capacitance changes after applying acceleration in the $\mathrm{x}$ and the $\mathrm{y}$ axes directions

employed, where two capacitors are used to calculate acceleration in the $z$ axis direction and for each of the $x$ and the $y$ axes, four capacitive groups are considered. The reason for the use of different capacitive groups is that the sensor, in addition to measuring acceleration in each axis direction, can afford to realize the amount of acceleration of each axis separately and precisely. Besides, due to taking difference in this structure, the effect of the acceleration of each axis on the measured acceleration of the other axis is highly negligible. If an external factor such as electromagnetic waves changes the values of any singular capacitor, the original output of the capacitor measured for realizing the acceleration will not change. In other words, designing is done in such a way that the acceleration of each axis does not affect the other two axes, and yet the external factors cannot disrupt system performance. In this study, for determining the dimensions of the constituting parts 
Table 3: Comparison of the suggested scheme with previous studies

\begin{tabular}{|c|c|c|c|c|c|}
\hline Print Year & Range of X Axis & Range of Y Axis & Range of Z Axis & $\begin{array}{c}\text { Area } / \mathrm{g} \\
\left(\mathrm{mm}^{2}\right)\end{array}$ \\
\hline 2007-(Hamaguchi et al. 2007) & $+-1 \mathrm{~g}$ & $+-1 \mathrm{~g}$ & $+-1 \mathrm{~g}$ & 1.08 & 1.14 \\
\hline 2006- (Bais and Majlis, 2006). & 0 & 0 & $+-5 \mathrm{~g}$ & 474 & .92 \\
\hline 2005-(Chae, et al.2005) & $+-1 \mathrm{~g}$ & $+-1 \mathrm{~g}$ & $+-1 \mathrm{~g}$ & 6800 & 63 \\
\hline 2009- (Zeimpekis and Kraft, (2009). & $+-5 \mathrm{~g}$ & 0 & 0 & 9500 & 33.2 \\
\hline 1996-(Chau et al.1996) & $+-5 \mathrm{~g}$ & 0 & 0 & 1.2 & 0.42 \\
\hline 2004- (Tsuchiya and Funabashi 2004) & 0 & 0 & $+-500 \mathrm{~g}$ & 1.1 & 1.21 \\
\hline 2005-(Bruschi et al. 2005) & $+-100 \mathrm{~g}$ & $+-100 \mathrm{~g}$ & 0 & 2 & 1.51 \\
\hline 2013-(Tavakoli, Sani, 2013) & $+-66 \mathrm{~g}$ & 0 & $+-30 \mathrm{~g}$ & 10 & 1.16 \\
\hline 2016-(Aydemir et al, 2016) & $+-71 \mathrm{~g}$ & $+-71 \mathrm{~g}$ & $+-231 \mathrm{~g}$ & 21.6 & 56.6 \\
\hline This work1 & $+-1111 \mathrm{~g}$ & $+-1111 \mathrm{~g}$ & $+-1100 \mathrm{~g}$ & 9 & 1.2 \\
\hline This work2 & +-2550 & +-2550 & +-2500 & 2.2 & 1.1 \\
\hline This work3 & +-198 & +-198 & +-198 & 29 & 10.5 \\
\hline
\end{tabular}

of the spring and the weight, the multi-objective optimization algorithm called NSGA2 has been adopted. This algorithm searches the five objectives, which are the dimensions of the elements, so that the best output results for the accelerometer can be obtained. Note that if any of the accelerometer factors such as dynamic range, operating frequency, and sensitivity is changed for a specific purpose, then the same structure can still be applied, and by using the suggested relations, only the geometric dimensions of the spring needs to be changed.

\section{References}

1. W. Yuan, H. Chang, W. Li, B. Ma, "Application of an Optimization Methodology for Multidisciplinary System Design of Micro gyroscopes," Journal of Microsystem Technologies, pp. 315-323,2006, https://doi.org/10.1007/s00542-005-0054-2.

2. J. Marek, H. P. Trah, Y. Suzuki, \& I. Yokomori, Sensors for Automotive Applications, vol. 4, Wiley Press, 2005.

3. J. J. Allen, Microelectromecanical System Design, $1^{\text {st }}$ Edition, CRC press, 2005.

4. S.Beeby, G. Ensell, M. Kraft, \& N. White, MEMS Mechanical Sensors, Artech House Press, (2004).

5. P. Ashok Kumar, R. G. K. S. Prakash, \& Rao, K. Srinivasa, "Design and Simulation of Capacitive Type Comb-Drive Accelerometer to Detect Heart Beat Frequency", International Journal of Biosen Bioelectron,pp.90-91,2017, https://doi.org/10.15406/ijbsbe.2017.02.00024.

6. G. Lammel, The Future of MEMS Sensors in our Connected World, 28th IEEE International Confer- ence on Micro Electro Mechanical Systems (MEMS), pp. 61-64, 2015,

https://doi.org/ 10.1109/MEMSYS.2015.7050886.

7. M. Kraft, Closed-loop Accelerometer Employing Oversampling Conversion, PhD Thesis, Coventry University, 1996.

8. M. S. Moghadam, H. Arefi, \& K. Mafinezhad, “A New Design and Optimization of Capacitive MEMS Accelerometer", International Journal of Simulation: Systems, Science \& Technology, pp. 23-32, 2014, https://doi.org/ 10.5013/IJSSST.a.14.01.04.

9. Y. Terzioglu, T. Kose, K. Azgin \& T. Akin, "Simple Out-of-Plane Capacitive MEMS Accelerometer Utilizing Lateral and Vertical Electrodes for Differential Sensing", IEEE Sensors, pp. 1-4, 2015, https://doi.org/10.1109/ICSENS.2015.7370306.

10. H. Tavakoli, \& E. A. Sani,"A New Method for Eliminating cross Axis Sensitivity in Two Axis Capacitive Micromachined Accelerometers", 21st Iranian Conference on Electrical Engineering (ICEE), pp. 595-598, 2013,

https://doi.org/10.1109/IranianCEE.2013.6599678

11. V. Benevicius, V. Ostasevicius, \& R. Gaidys, "Identification of Capacitive MEMS Accelerometer Structure Parameters for Human Body Dynamics Measurements", Sensors Journal, pp. 11184-11195, 2013,

https://doi.org/10.3390/s130911184.

12. S. Tez, U. Aykutlu, M. M. Torunbalci, \& T. Akin, "A Bulk-Micromachined Three-Axis Capacitive MEMS Accelerometer on a Single Die", IEEE Journal of Microelectromechanical Systems, pp. 12641274, 2015, https://doi.org/ 10.1109/JMEMS.2015.2451079.

13. C. Acar, \& A. Shkel, MEMS Vibratory Gyrosceps, Springer Publishing Company, 2008. 
14. M.Bao, H. Yang, "Squeeze film air damping in MEMS", Journal of Sensors and Actuators, pp. 3-27, 2007, https://doi.org/ 10.1016/j.sna.2007.01.008.

15. H. G. Momen, H. Tavakoli, E. A. Sani, "A 3-Axis MEMS Capacitive Accelerometer Free of Cross Axis Sensitivity", 24th Iranian Conference on Electrical Engineering (ICEE), pp. 1491-1494, 2016, https://doi.org/10.1109/IranianCEE.2016.7585757

16. X, Zhou, L. Che, S. Liang, Y. Lin, X. Li, Y.Wang, “Design and Fabrication of a MEMS Capacitive Accelerometer with Fully Symmetrical Double-Sided H-Shaped Beam Structure", Journal of Microelectronic Engineering, pp. 51-57, 2015, https://doi.org/10.1016/j.mee.2014.10.005.

17. K. Delfan Hemmati, M. Behzad Fallahpour, A Golmakani, K. Delfan Hemmati, "A High-Speed Hybrid Full Adder with Low Power Consumption", IEICE Electronics Express, 1900-1905, 2012, https://doi.org/10.1587/elex.9.1900.

18. H. Hamaguchi, K. Sugano, T. Tsuchiya, O. Tabata, "A Differential Capacitive Three Axis Soi Accelerometer Using Vertical Comb Electrodes", IEEE International Solid-State Sensors, Actuators and Microsystems Conference, pp. 1483-1486, 2007, https://doi.org/ 10.1109/SENSOR.2007.4300425.

19. B. Bais, B. Y. Majlis, "Structure Design and Fabrication of an Area changed Bulk Micromachined Capacitive Accelerometer, IEEE International Conference on Semiconductor Electronics, pp. 29-34, 2006, https://doi.org/ 10.1109/SMELEC.2006.381014.

20. J. Chae, H. Kulah, Najafi, K. "A Monolithic ThreeAxis Micro-g Micromachined Silicon Capacitive Accelerometer, Journal of Microelectromechanic Systems", pp. 235-241, 2005, https://doi.org/10.1109/JMEMS.2004.839347.

21. I. Zeimpekis, M. Kraft, "Single Stage Deflection Amplification Mechanism in a SOG Capacitive Accelerometer", Journal of Procedia Chemistry, pp. 883-886, 2009,

https://doi.org/org/10.1016/j.proche.2009.07.220

22. K. H. L. Chau, S. R. Lewis, y. Zhao, R. T. Howe, S. F. Bart, R. G. Marcheselli, "An Integrated ForceBalanced Capacitive Accelerometer for Low-g Applications", Proceedings of the International Solid-State Sensors and Actuators Conference, pp. 472-476, 1996, https://doi.org/ 10.1109/SENSOR.1995.717294.

23. T. Tsuchiya, H. Funabashi, "A Z-Axis Differential Capacitive SOI Accelerometer with Vertical Comb Electrodes", 17th IEEE International Conference on Micro Electro Mechanical Systems, pp. 378-383, 2004, https://doi.org/ 10.1109/MEMS.2004.1290637.
24. P. Bruschi, A. Nannini, D. Paci, F. Pieri, "A Method for Cross-Sensitivity and Pull-In Voltage Measurement of MEMS Two-Axis Accelerometers", Sensors and Actuators A: Physical, Elsevier, pp. 185-193, 2005, https://doi.org/10.1016/j.sna.2005.04.028

25. A. Aydemir, Y. Terzioglu, T. Akin, "A new design and a fabrication approach to realize a high performance three axes capacitive MEMS accelerometer", Sensors and Actuators A: Physical, Elsevier, pp. 324-333, 2016, https://doi.org/10.1016/j.sna.2016.04.007.

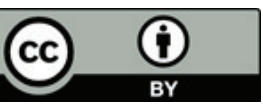

Copyright (c) 2020 by the Authors. This is an open access article distributed under the Creative Commons Attribution (CC BY) License (https://creativecommons.org/licenses/by/4.0/), which permits unrestricted use, distribution, and reproduction in any medium, provided the original work is properly cited.

Arrived: 04. 09. 2019

Accepted: 29.03. 2020 